\title{
Suppository Effect of Aqueous Root Extract of Moringa oleifera on Alcohol Induce Liver Toxicity in Wistar Rats
}

\author{
Eteng O. E. ${ }^{\star}$, Grace Ekpo ${ }^{2}$, Joe Enobong ${ }^{2}$, Iwara Arikpo ${ }^{2}$, Saviour Ufot ${ }^{2}$, \\ Kenyoh Abam ${ }^{2}$, Archibong Nsa ${ }^{3}$, Victor Ekam ${ }^{2}$ and Eyong Ubana ${ }^{2}$ \\ ${ }^{1}$ Department of Biochemistry, College of Bioscience, Federal University of Agriculture, Abeokuta, \\ Ogun State, Nigeria. \\ ${ }^{2}$ Department of Biochemistry, College of Basic Medical Science, University of Calabar, Calabar, \\ Nigeria. \\ ${ }^{3}$ Department of Physiology, College of Basic Medical Science, University of Calabar, Calabar, Nigeria.
}

\section{Authors' contributions}

This work was carried out in collaboration among all authors. Authors EOE and GE conceived the idea and designed the research work. Authors JE, KA and SU carried out the experiment, author VE supervised the work. Author JE did the statistical analysis. Authors EOE and GE wrote the paper and finally professor author EU read and approved the final manuscript.

Article Information

DOI: 10.9734/ARRB/2019/v33i630139 Editor(s):

(1) Dr. Jean-Marie Exbrayat, Professor, Universite Catholique de Lyon, France. Reviewers:

(1) K. D. Mini, Mahatma Gandhi University, India. (2) Oshim, Ifeanyi Onyema, Nnamdi Azikiwe University, Nigeria. Complete Peer review History: http://www.sdiarticle4.com/review-history/50593

Original Research Article

Received 10 June 2019

Accepted 15 August 2019 Published 05 December 2019

\begin{abstract}
Introduction: Moringa oleifera root is the most underutilized part of the plant and it is rich in many phytochemicals.

Aim of the Study: This study was carried out to evaluate the effect of Standardized and characterized aqueous root extract of Moringa oleifera following the administration of alcoholinduced liver damage in albino wistar rats.

Materials and Methods: Thirty (30) experimental rats weighing 100-120 g were randomly divided into 6 groups of 5 rats each. Group 1, the normal control group was given just rat feed and water, group 2, negative control was administered alcohol only $(1.5 \mathrm{ml} / \mathrm{kg}$ body weight), rats in group 3, 4 and 5 received combined administration of alcohol $1.5 \mathrm{ml} / \mathrm{kg}$ body weight and 200, 400 and 600
\end{abstract}


$\mathrm{mg} / \mathrm{kg}$ body weight of characterized aqueous root extract of Moringa oleifera respectively, group 6 rats were administered $250 \mathrm{mg} /$ body weight of extract only. At the end of fourteen days (14) the experimental rats were then sacrificed and the serum liver enzymes were then assayed.

Results: The results obtained from the laboratory was analyzed using one-way ANOVA and posthoc test was done afterwards. Rats fed alcohol only produced significant increase in the levels of enzyme markers of tissue damage (AST, ALT and ALP) compared to normal control rats. Rats in group 3, 4 and 5 that were post treated with 200, 400 and $600 \mathrm{mg} / \mathrm{kg}$ body weight of extract and they had significant decrease $(P<0.05)$ in the levels of these enzyme markers in a dose-dependent manner compared to the negative control. The extract control group had no significant increase $(P<0.05)$ in the levels of the enzyme markers when compared to the normal control; however, there was a significant increase in the serum activity of ALP of the extract control group when compared with the normal control.

Conclusion: The present study exhibited a potent hepatoprotective effect against liver injury caused by alcohol administration. This suppository effect could be related to the antioxidant's properties of Moringa oleifera that is rich in flavonoids and phenolic constituents of the extracts may contribute to their enzyme action.

Keywords: Moringa oleifera; AST aspartate transaminase; alanine transaminase ALT; alkaline phosphatase ALP.

\section{INTRODUCTION}

\subsection{Background Information}

Medicinal plants are plants that are used in attempt to maintain health, to be administered for a specific condition or both, whether in modern medicine or in traditional medicine [1]. They are widely used in both developing and developed societies as sources of drugs or herbal extracts for various chemotherapeutic purposes mainly because they are readily available and cheaper than modern medicines. On a scientific ground, these plants are used because of their active phytochemical constituents. The medicinal and pharmacological activities of medicinal plants are often attributed to the presence of secondary plants metabolites known as phytochemicals. Unlike the ubiquitous macromolecules of primary metabolites like monosaccharide's, polysaccharides, amino acids, proteins, nucleic acids and lipids which are present in all plants, secondary metabolites with medicinal properties are found only in few plants species and they have more medicinal value. Secondary plants metabolites with reported medicinal properties include alkaloids, phenolics, saponins, glycosides and terpenoids [2]. They offer the anti-microbial, anti-oxidative, anti-inflammatory properties of plants. Natural constituents based on plant can be derived from every plant part like roots, bark, seeds, flowers, leaves etc. [3].

Phytochemicals are chemical compounds produced by plants through primary or secondary metabolism [4]. They are non-nutritive plant chemicals that have disease preventive or protective properties, they offer plants natural defense system providing protection against such things as attack from insects, grazing animals and microbes. Examples include flavonoids, phenols, terpenes, alkaloids etc. They contribute to plant colour, aroma and flavour [5]. M. oleifera, which is also known as the "Miracle Tree" and "Mother's Best Friend," has been named the most nutrient-rich plant. Other than having a high concentration of vitamin $A$, vitamin $\mathrm{C}$, potassium, and calcium, the plant contains all the essential amino acids [6]. Different parts of the Moringa oleifera tree have been established as being a good source of unique glucosinolates, flavonoids and phenolic acids [7]. carotenoids, tocopherols, polyunsaturated fatty acids, highly bio-available minerals and folate [8].

Worldwide adults consume about average 5liters of pure alcohol from beer, wine and spirits per year. The average alcohol consumption is high in Europe followed by America and then Africa. It tends to increase with economic development. Alcohol consumption is the leading risk factor for disease burden in low mortality developed countries [9]. Alcohol causes 1.8 million deaths (3.2\% of total) and a loss of 58.3 billion (4\% total of disability) adjusted life years [10]. Excessive alcohol consumption is widely associated with liver damage [11]. Just along the streets of Nigeria today, one is sure to find at least one or two herbal concoction sellers either hawking or situated somewhere in the vicinity. This herbal brew known popularly as agbo has drawn quite a significant attention from the nation's health sector with lots of debates trailing it. In recent times however, this trend has taken on another 
dimension in the country as consumption of the locally brewed gin mixed with some roots and herbs has reached an all-time high. While some people are quick to attribute this trend to poverty level in the country which has financially incapacitated many citizens, others feel it is as a result of lack of adequate provision of medical care. However, for whatever reason and with the recent indiscriminate sell of agbo that is attracting more subscribers from other classes in the society and despite fears that the consumption of agbo would be detrimental to health, the number of people patronizing it keeps soaring. The notion at the back of an average of agbo consumer's mind is to keep healthy in the most natural way without any negative side effect from chemical reactions.

The aim of this study is to determine the effect of aqueous root extract of $M$. oleifera following the administration of alcohol-induced liver damage in wistar rats.

\section{MATERIALS AND METHODS}

\subsection{Apparatus/Chemical Used}

Sample ( $M$. oleifera roots), grinding machine, electronic weighing balance, beakers, funnel, plastic buckets, filter paper (what man filter paper No 1), measuring cylinder, sieve basket, chess cloth, thermo-regulated water bath, palletized rat feed, alcoholic beverage (tombo), water bottles, saw dust, poly-carbonated cages, hand gloves, syringes, needles, spectrophotometer, cuvettes, centrifuge, reagent kits for determination of aspartate transaminase, alanine transaminase and alkaline phosphatase.

\subsection{Sample Collection}

Fresh sample of Moringa oleifera roots were harvested from the University of Calabar Staff Quarters. The roots were then chopped into smaller fragments, washed properly with tap water to remove debris and other physical contaminants and then air dried at room temperature for two weeks.

\subsection{Preparation of Extract (Cold Maceration Method of Extraction)}

The mature root of moringa oleifera were obtained from the University of Calabar, Botanical Garden and identified by Dr. Francis Eko, of Botany Department university of Calabar, Calabar. Voucher specimen deposited in the
Departments herbarium number 2435 was kept for future reference. The root was rinsed with water to remove debris and sand and then sun dried. The dried samples were pulverized to powder form using grinding machine. The grinded sample was then weighed using an electronic weighing balance and put in a plastic bucket. $2700 \mathrm{ml}$ of water was then added to the plastic bucket containing the sample. The soaked sample was allowed to stand for 24 hours, after which it was first filtered using a sieve basket and then chess cloth. The filtrate obtained was then filtered again using what man filter paper No 1 . The filtrate obtained was collected in beakers and then placed into a thermo regulator water bath with temperature set at $50^{\circ} \mathrm{C}$ and allowed to concentrate. The extract gotten was then collected into plastic vials and then stored in the refrigerator at $4^{\circ} \mathrm{C}$ to be used for further experiment.

\subsection{Toxicity Study on Moringa oleifera}

According to one acute toxicity study of various extracts of Moringa oleifera roots, results of that study showed a safe range. The LD50 for the aqueous root extract was $15.9 / \mathrm{kg}$. The results were supported by the work done by [12].

\subsection{Experimental Procedure}

Thirty (30) albino wistar rats weighing 100-120kg from the animal house of the Department of Biochemistry, University of Calabar were used. The animals were acclimatized for a week in the animal house, they were fed with standard rodent pellets and water was provided ad libitum. The animals were maintained there at standard conditions of temperature and relative humidity. The rats were then afterwards divided into 6 groups of 5 rats each.

\subsection{Administration of Alcohol and Root Extract}

Alcohol and root extract of $M$. oleifera were administered orally with the aid of a studded needle and syringe. During the first 3 days, rats in group 2, 3, 4 and 5 were induced with subchronic liver damage orally using a commonly available alcoholic beverage, Tombo $(4.82 \%)$ at a dose of $1.5 \mathrm{ml}$ per body weight only after which on the $4^{\text {th }}$ day to the last day $\left(14^{\text {th }}\right)$, they were given aqueous root extract of MO shortly after alcohol administration. At the end of the treatment period the rats were reweighed and then were sacrificed. 
Table 1. Experimental design

\begin{tabular}{|c|c|c|c|}
\hline Group & Designation & Treatment & Dose \\
\hline 1 & NC & Water & Ad libitum \\
\hline 2 & $\mathrm{NgC}$ & Alcohol & $1.5 \mathrm{ml}$ of alcohol/bw \\
\hline 3 & AMR1 & Alcohol and rMO & $1.5 \mathrm{ml}$ of alcohol $/ \mathrm{bw}+1.5 \mathrm{ml}$ of $200 \mathrm{mg}$ of Rmo \\
\hline 4 & AMR2 & Alcohol and rMO & $1.5 \mathrm{ml}$ of alcohol $/ \mathrm{bw}+1.5 \mathrm{ml}$ of $400 \mathrm{mg}$ of $\mathrm{Rmo}$ \\
\hline 5 & AMR3 & Alcohol rMO & $1.5 \mathrm{ml}$ of alcohol $/ \mathrm{bw}+1.5 \mathrm{ml}$ of $600 \mathrm{mg}$ of $\mathrm{Rmo}$ \\
\hline 6 & EC & Rmo & $1.5 \mathrm{ml}$ of $250 \mathrm{mg}$ of $\mathrm{Rmo}$ \\
\hline
\end{tabular}

\subsection{Collection and Preparation of Blood for Analysis}

At the end of the $14^{\text {th }}$ day treatment period, the animals were anesthetized with chloroform. They were then dissected and their blood collected with sterile syringes by cardiac puncture into sterile labeled plain vials and was allowed to clot for about 2 hours, they were then centrifuged at $3000 \mathrm{~g}$ for 15 minutes to allow for separation of serum from blood cells. The serum was then precipitated into a plain and well labeled vial for liver function test.

\subsection{Ethical Approval}

Ethical approval was also sought from the committee, faculty of basic medical science, university of Calabar, Calabar.

\subsection{Statistical Analysis}

Quantitative data were analyzed using one-way analysis of variance (ANOVA), followed with a post hoc (Duncan) test for significant values. Pvalue < 0.005 was considered statistically significant. Statistical package for the social sciences application software, SPSS version 20 was used for statistical analysis and the charts were plotted using Microsoft-Excel application software 08. Data are expressed as mean \pm standard error of mean (SEM).

\section{RESULTS AND DISCUSSION}

From the result obtained in Table 2 there were significant increase in AST concentration in all the groups when compared to the normal control group, NC (36.59 \pm 0.90$)$. while the negative control, NgC, AMR1, AMR2 and the AMR3 group AST concentration were significantly higher than the normal control group. There was no statistically significant difference (at $\mathrm{P}<0.005$ ) between the normal control group and the extract control group (39.66 \pm 1.72$)$. The negative control group had the highest AST mean concentration $(61.85 \pm 1.22)$ and is statistically significantly different from every other group. Though, there was no significant difference between the AMR1

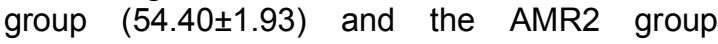
(49.66 \pm 2.69$)$ and also between the AMR2 group and AMR3 group $(47.76 \pm 0.77)$, there was a statically significant difference between the AMR1 group and the AMR3 group (as seen in Fig. 1). Also, they were significant increase $(\mathrm{P}<0.05)$ in ALT concentrations in all the groups except the extract treated group when compared to the normal control $(29.87 \pm 0.20)$. The increase in the extract control group $(31.72 \pm 0.77)$ is not statistically significantly different from the normal control observed in Fig. 2. The negative control group recorded the highest mean ALT concentration $(59.66 \pm 2.57)$ which is significantly different from other groups. The AMR1 group $(52.76 \pm 0.33)$ was significantly lower than the negative control and higher than the AMR2 and AMR3 group. The increase in ALT concentration in the AMR2 group $(42.97 \pm 0.92)$ is not significantly $(p<0.05)$ different from the increase in ALT concentration in the AMR3 group $(40.76 \pm 0.33)$. The was also a significant increase $(\mathrm{P}<0.05)$ in ALP concentration in all the groups when compared to the control $(15.28 \pm 0.11)$. The increase in ALP concentration between the AMR1 (27.64 \pm 0.41$)$, AMR2 (25.79 \pm 0.99$)$, AMR3 $(25.31 \pm 0.93)$ and the negative control, $\mathrm{NgC}$ $(27.05 \pm 0.22)$ is statically insignificantly different $(P>0.05)$ but significantly different from the extract control group (18.06 \pm 1.02$)$ seen in Fig. 3.

\subsection{Discussion}

The suppository effect of aqueous root extract of Moringa oleifera on liver enzymes was investigated. As it is well known, the liver appears to be due to its unique metabolism function the most common target organ of any toxicity. Alcohol is one of the chemical hepatoxin known for inducing characteristics feature similar to those of acute hepatitis in humans. The most commonly and routinely assayed enzyme 
includes serum transaminase and alkaline phosphatase [13]. These are non-specific liver enzymes. Those specific to the liver includes ornithine carbonyl transferase, $5^{1}$ nucleotidase. From the results obtained from the study there was a significant in all the liver enzymes which alter the integrity of the liver cells following the induction of alcohol. These results are therefore in line with the study on Acute injury to hepatocytes alters their transport function and membrane permeability leading to leakage of marker enzymes from the cells [14]. Also, the intracellular mechanisms of injury were due to alcohol in hepatocytes which formed the reactive metabolites, depletion of the antioxidant, glutathione. The liver is highly susceptible to alcohol damage because it is the primary site of alcohol metabolism. Alcohol induced liver damage are of three categories namely, fatty liver, alcoholic hepatitis and liver cirrhosis [15]. Fatty liver is the deposition of fat in the liver; it discolors the liver from the normal reddish brown to a yellowish coloration, this condition is reversible. Hepatitis on the other hand, is the inflammation of the liver, it is reversible by abstinence else it progresses to liver cirrhosis. Liver cirrhosis is an end stage condition characterized by fibrosis, which is the formation of scar tissue. Usually in liver cirrhosis the liver damages beyond repair, the only option available is liver transplantation. Most of the liver damages induced by alcohol consumption are attributed to alcohol metabolism and the byproducts of that metabolism [16]. However, from the study it has shown that aqueous root extract given at moderate to high dose may have ameliorate the toxicity effect of alcohol. The toxic by-products of alcohol metabolism are acetaldehyde and free radicals [17]. These compounds when generated can complex with our macromolecules such as proteins, lipids and nucleic acids forming adducts, lipid peroxidase and other reactive oxygen species. The products could also deplete the concentrations of antioxidant in the liver. Acetaldehyde adducts are recognized as foreign by the immune system hence they invoke immune responses against them. The lipid peroxidase distorts the hepatocellular membrane, makes them porous thus allowing liver enzymes to concentrate in plasma.

Assessment of liver injury was determined by serum concentrations of AST, ALT and ALP one of the most commonly indicated markers for liver toxicity. When the liver cell plasma membrane is damaged, a variety of enzymes normally located in the cytosol are released into the bloodstream. Their amount in the serum is a useful quantitative marker of the extent and type of hepatocellular damage.

Increased activities of serum enzymes were observed after the administration of alcohol compared to the normal control, NC. The present study correlates with other studies showing significant increase of ALT and AST values after administration of hepatotoxicant such as alcohol.

In this study the negative control which was administered alcohol only had a remarkably increase in serum transaminase (AST and ALT) when compared to the normal control. A study done by [18]. Also had a similar result. The animals treated with alcohol only had a significant hepatic damage as indicated by the elevated levels of serum enzymes markers of tissue damage studied. Moringa oleifera is rich in anti-oxidants [19]. The major bioactive compounds which contribute to the anti-oxidants activity of Moringa oleifera are the phenolics such as kaempferol, quercetin, flavonoids, and these compounds scavenge free radicals and

Table 2. Comparison of enzymes concentrations in the different experimental groups

\begin{tabular}{lllll}
\hline Groups & Designation & \multicolumn{3}{c}{ Enzyme activities } \\
\cline { 3 - 5 } & & AST (U/L) & ALT (U/L) & ALP (U/L) \\
\hline $\mathbf{1}$ & NC & $36.59 \pm 0.90^{\mathrm{a}}$ & $29.87 \pm 0.20^{\mathrm{a}}$ & $15.28 \pm 0.11^{\mathrm{a}}$ \\
$\mathbf{2}$ & $\mathrm{NgC}$ & $61.85 \pm 1.22^{\mathrm{d}}$ & $59.66 \pm 2.57^{\mathrm{d}}$ & $27.05 \pm 0.22^{\mathrm{c}}$ \\
$\mathbf{3}$ & AMR1 & $54.40 \pm 1.93^{\mathrm{c}}$ & $52.76 \pm 0.33^{\mathrm{c}}$ & $27.64 \pm 0.41^{\mathrm{c}}$ \\
$\mathbf{4}$ & AMR2 & $49.66 \pm 2.69^{\mathrm{bc}}$ & $42.97 \pm 0.92^{\mathrm{b}}$ & $25.79 \pm 0.99^{\mathrm{c}}$ \\
$\mathbf{5}$ & AMR3 & $47.76 \pm 0.77^{\mathrm{b}}$ & $40.76 \pm 0.33^{\mathrm{b}}$ & $25.31 \pm 0.93^{\mathrm{c}}$ \\
$\mathbf{6}$ & EC & $39.66 \pm 1.72^{\mathrm{a}}$ & $31.72 \pm 0.77^{\mathrm{a}}$ & $18.06 \pm 1.02^{\mathrm{b}}$ \\
\hline
\end{tabular}
Means for groups in homogenous subsets displayed are significant at $p<0.05, n=5$

There was statistically significant difference between the groups and the liver enzymes [F $(5,11)$ AST 25.77, $P=0.0001, A L T$ 163.29, $P=0.0001, A L P$ 46.32, $P=0.0001$ ]; Keys: NC - Normal control; EC - Extract control; NgC - Negative control; AMRn - Groups administered with alcohol and extract $(n=1,2,3)$ 
chelates metal ions [20]. The groups treated with the extract had a significant decrease in the serum transaminases when compared to the negative control. The extract control group was not statistically significantly different from the normal control group. This is probably due to the presence of the antioxidant's properties present in the plant that scavenge the free radicals to induces hepatocellular damage. Because the bioactive components of the plant are very rich in flavonoids and phenolic acids (Amaglo et al., 2010; Coppin et al., 2013), carotenoids (Sani et al., 2014a), tocopherols, (Sani et al., 2014b), polyunsaturated fatty acids (Sani et al., 2014c), highly bio-available minerals and folate (Sani et al., 2014d).

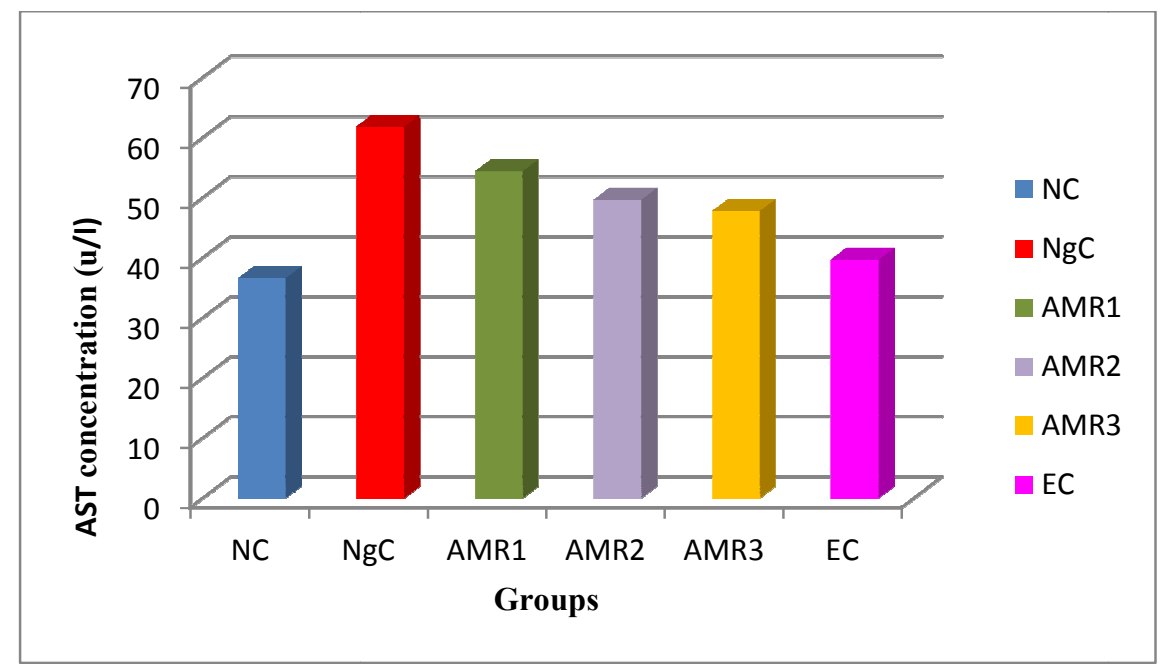

Fig. 1. Comparism of aspartate transaminase concentrations in the different experimental groups

Values are expressed as mean \pm SEM, $n=5$.; NC - normal control; $N g C$ - negative control; AMRn - Groups administered with alcohol and extract $(n=1,2,3) ; E C$ - Extract control

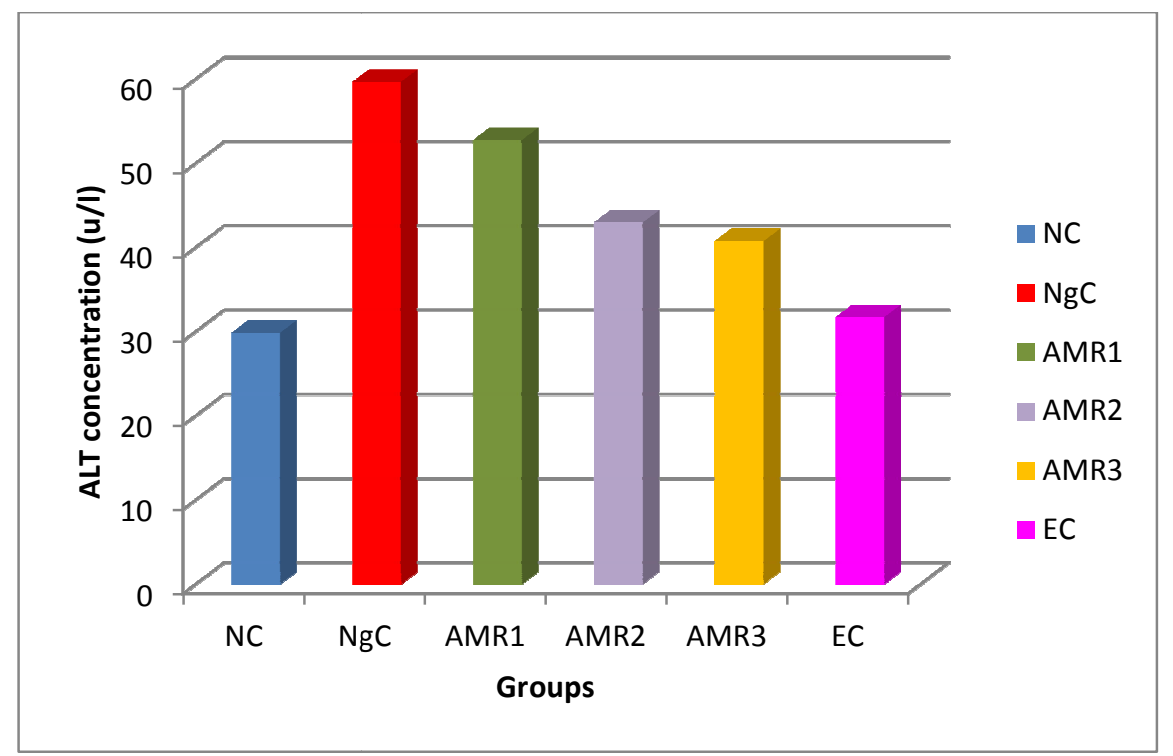

Fig. 2. Comparison of alanine transaminase concentrations in the different experimental groups

Values are expressed as mean \pm SEM, $n=5$.; NC-normal control; NgC - negative control; AMRn - Groups administered with alcohol and extract $(n=1,2,3) ; E C-$ Extract control 


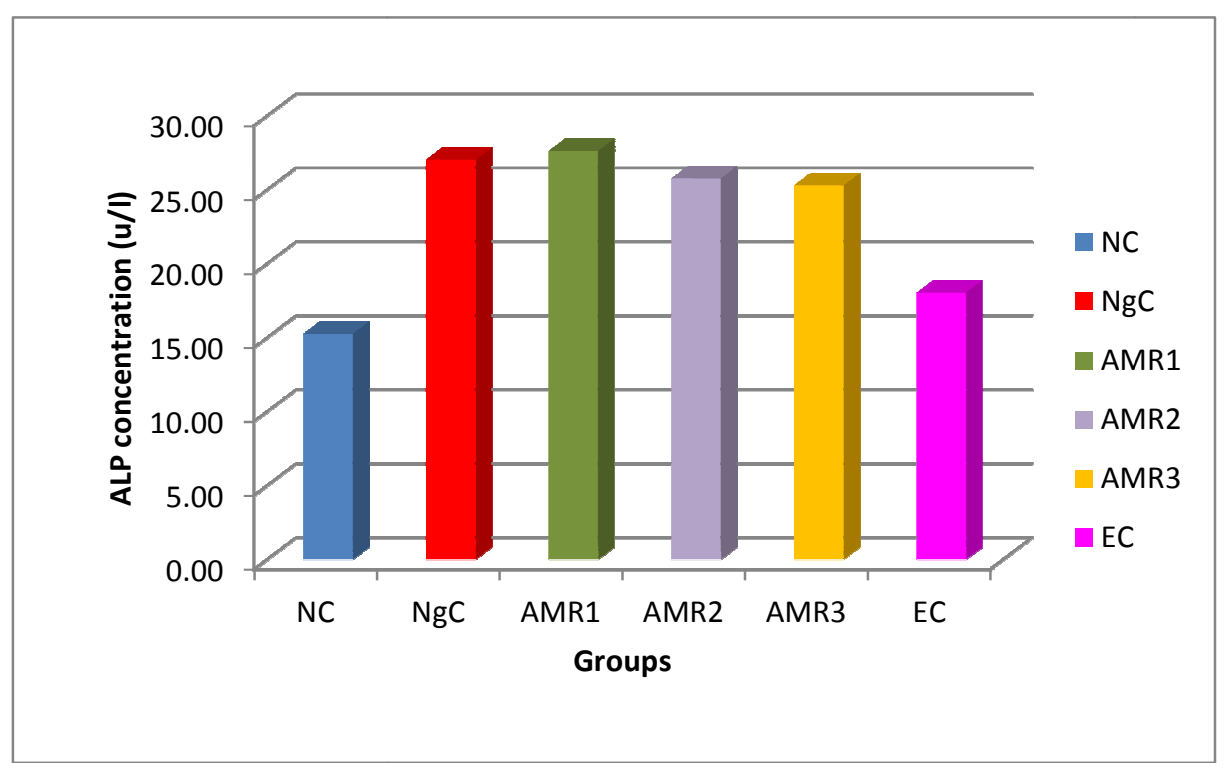

Fig. 3. Comparison of alkaline phosphatase concentrations in the different experimental groups

Values are expressed as mean $\pm S E M, n=5$.; $N C$ - normal control; $N g C-$ negative control; $A M R n-$ Groups administered with alcohol and extract $(n=1,2,3) ; E C-$ Extract control

\section{CONCLUSION}

The present study exhibited a potent hepatoprotective effect against liver injury caused by alcohol administration. We therefore conclude that aqueous root extract of Moringa oleifera have a broad safety potential for therapeutic uses. Therefore, it could be on record that the aqueous root extract of Moringa oleifera will help in liver toxicity for people suffering from liver cirrhosis. The above mention used results represented on this study will benefit our future studies of Moringa oleifera as it will be used as alternative remedy in the treatment and management of liver damage.

\section{COMPETING INTERESTS}

Authors have declared that no competing interests exist.

\section{REFERENCES}

1. Ahn K. The worldwide trend of using botanical drugs and strategies for developing global drugs. BMB Reports. 2017;50(3):111-116.

2. Ebong P. History of medicinal plants. In: Phtyomedicine: Panacae for Primary Health Care Delivery in Nigeria. University of Calabar Press. 2015a;5-13.
3. Gordon M, David J. Natural product drug discovery in the next millennium. Pharmaceutical Biology. 2001;39:8-17.

4. Harborne J, Baxter H. General introduction. In: Phytochemical dictionary a handbook of bioactive compounds from plants, 2nd edition. London: Taylor \& Francis. 1999;vii.

5. Ebong P. History of medicinal plants. In: Phtyomedicine: Panacae for Primary Health Care Delivery in Nigeria. University of Calabar Press. 2015a;5-13.

6. Mahmood K, Mugal T, Haq I. Moringa oleifera: A natural gift - A review. Journal of Pharmaceutical Sciences and Research. 2010;2:775-781.

7. Amaglo N, Bennet $\mathrm{R}$, Curto L. Profiling selected phytochemicals and nutrients in different tissues of the multipurpose tree Moringa oleifera Lam grown in Ghana. Journal of Food Chemistry. 2010;122: 1047-1054

8. Saini R, Shetty N, Giridhar P. Carotenoid content in vegetative and reproductive parts of commercially grown Moringa oleifera Lam. cultivars from India by LCAPCI-MS. European Food Research and Technology. 2014a;238:971-978.

9. Rehn J, Eschmann S. Global monitoring of average volume of alchohol consumption. Cozialund Pruventrimedizin. 2002;47:4858. 
10. WHO. Management of substance abuse. Part 1, Global Status Report on Alcohol, Geneva; 2004.

11. Heatcote E. Management of primary biliary cirrhosis. The American studies of liver disease practice guidelines. Hepatology 2000;31:1005-1013.

12. Adedapo A, Mogbojuri O, Emikpe B. Safety evaluation of the aqueous extract of the leaves of Moringa oleifera in rats. Journal of Medicinal Plants Research. 2009;3(8):586-591.

13. Uboh F. Clinical use of enzymes. In: Conceptual Enzymology and Biological Reactions, (revised edition). Demerx Scientific press limited. 2012;340-347

14. Zhang $X$, Shan $P$, Otterbein L, Alam J, Flavell $R$, Davis $R$, Choi $A$, Lee $P$. Carbonmonoxide inhibition of apoptosis during ischemia reperfusion lung injury is dependent on the p38 mitogenactivated protein kinase pathway and involves caspase. Journal of Biological Chemistry. 2003;278:12481258.

15. French S, Nash J, Shitabata P, Kachi K, Hara C, Chedid A, Mendenhall V.
Pathology of alcohol liver disease. A Cooperative Study Group Seminars in Liver Disease. 1993;13(13):104-169

16. Lohr R. Acute alcohol intoxication and alcohol withdrawal, In: Hospital Medicine, $2^{\text {nd }}$ edition. Philadelphia: Lippincott, Williams and Wilkins. 2005;24-30.

17. Seitz H, Becker P. Alcohol metabolism and cancer risk. Alcohol Health and Research World. 2007;30(11):38-47.

18. Nadro $P$, Singh $S$. Serum transaminases: Quo Vadis. Biochemistry and Analytical Biochemistry. 2006;5:260.

19. Chumark $P$, Khunawat $P$, Sanvarinda $Y$, Phornchirasilp S, Morales P, Phivthong Ngam L, Klaiupsom P. The in vitro and ex vivo antioxidant properties, hypolipidaemic and antiatherosclerotic activities of water extract of Moringa oleifera Lam leaves. Journal of Ethnopharmacology. 2008;116: 439-446.

20. Chanda S, Dave R. In vitro models for antioxidant activity evaluation and some medicinal plants possessing antioxidant properties: An overview. African Journal of Microbiology and Research. 20093:981996.

(c) 2019 Eteng et al.; This is an Open Access article distributed under the terms of the Creative Commons Attribution License (http://creativecommons.org/licenses/by/4.0), which permits unrestricted use, distribution, and reproduction in any medium, provided the original work is properly cited.

Peer-review history:

The peer review history for this paper can be accessed here: http://www.sdiarticle4.com/review-history/50593 